\title{
Paper
}

\section{Snap-Through Behavior of Arch Shell for Button or Switch Design in Electronic Products}

\author{
Thomas Jin-Chee LiU*† Member, NaI-Pin LiN ${ }^{\dagger} \quad$ Non-member
}

(Received January 27, 2018, revised July 05, 2018)

\begin{abstract}
Using the non-linear finite element analysis, this paper has discussed the snap-through behavior of the arch shell applied in button or switch design. According to the research results, the design guidelines are provided for product engineers. The snap-through behavior of the arch is affected by many conditions such as working temperature, material type, geometry, and maximum indentation. The JIS SUS $301 \mathrm{EH}$ stainless steel is a good choice to provide the stable performance.
\end{abstract}

Keywords: Snap-through, Finite element, Arch shell, Click ratio

\section{Introduction}

Buttons and switches are important components in electronic products such as digital cameras, mobile phones, and audio players. These components are used to control and transfer the electrical currents or signals. Fig. 1 illustrates the cross-sectional structure and working motion of the button and switch. When people's finger presses on a button or switch such as Fig. 1, they can feel a click or jump motion. This click or jump motion is achieved by the snap-through behavior of the arch or dome structure as shown in Fig. 2 . Of course, the arch and dome are key components of the button and switch.

The snap-through behavior is an unstable and buckling phenomenon. Fig. 3 illustrates the force-displacement $(F-$ $v$ ) relation and snap-through behavior of an arch or dome during the indentation. When the applied force approaches the critical point a, the structure will jump or snap suddenly along the a-c path. If the displacement-control method is adopted, the jump motion follows the a-b-c path.

The snap-through problem is a typical topic in solid mechanics. This mechanical problem has been studied by using analytical or numerical methods in past references [1] [7]. On the other hand, the snap-through deformation of the arch or dome has been adopted for designing the button and switch in past decades. The arch or dome structures with small size and long durability are required for electronic products. Ninomiya et al. have reported the case study of metal dome design in mobile communication equipments [8] [9]. They designed high quality and small sized metal dome for the key switch of the mobile phone. Using the finite element method, the snap-through deformation and optimum design of the dome were obtained [9].

Although the arch and dome design are mature tech-

\footnotetext{
* Corresponding author: jinchee@mail.mcut.edu.tw

Department of Mechanical Engineering, Ming Chi University of Technology. Taishan, New Taipei City, Taiwan.
}

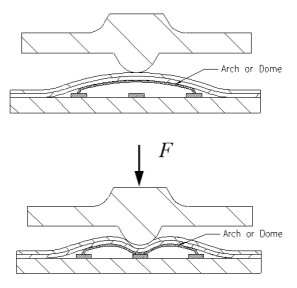

(a)

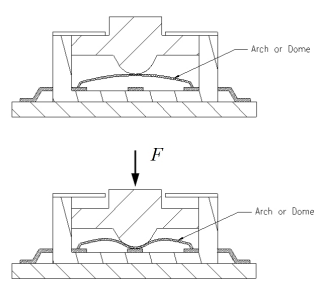

(b)

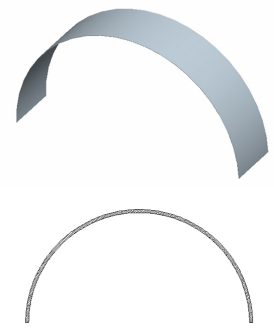

(a)

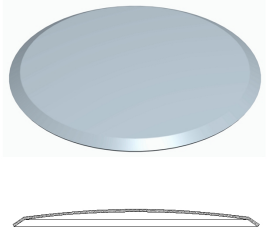

(b)
Figure 2: (a) Arch; (b) Dome

nologies in electronic and mechanical industries, there are few references for this research topic in academic journals. Also, many technical reports and documents from button or switch companies only focused their attentions on their product performance and manufacture. From academic point of view, this paper plans to understand and discuss the structural behavior and snap-through deformation of the arch shell structure applied in button or switch design. Furthermore, this paper will provide the information and design guidelines for the button and switch. Using the non-linear finite element analysis and the ANSYS software, the large displacement, contact condition and elasto-plastic stress-strain relation are considered in this paper. The material, geometry and assembly properties of the arch shell will be discussed for obtaining the design guidelines. 


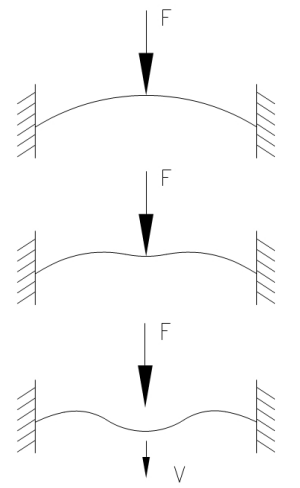

(a)

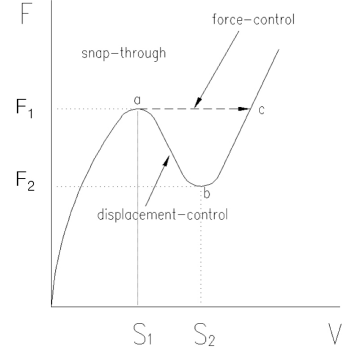

(b)
Figure 3: (a) Snap-through phenomenon of arch or dome; (b) Force-displacement $(F-v)$ relation of snap-through deformation

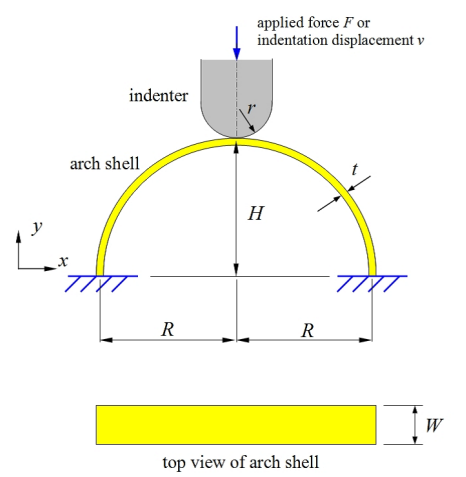

Figure 4: Problem statement of this study

\section{Problem Statement}

Fig. 4 shows the problem statement of this study. The arch shell structure with thin thickness has dimensions: $R, H$, $W$ and $t$. The circular indenter with radius $r$ presses on the arch shell and then the snap-through deformation can be obtained. Both ends of the arch are fixed. Due to the relative rigidity, the indenter is assumed as a rigid body in the structural analysis. The arch shell is made of metal such as aluminum or steel. In this study, three types of materials are considered:

\section{(1) JIS SUS $301 \mathrm{EH}$ stainless steel \\ (2) Al-Mn 3004 aluminum alloy \\ (3) 6061-T6 aluminum alloy}

Table 1 lists the material constants of above three materials. Fig. 5 shows the true stress-strain curves for the elastoplastic analysis. The data in Fig. 5(a) and 5(b) are converted from the engineering stress-strain curves obtained directly by the tensile test. The data in Fig. 5(c) is converted from ref. [10] [12].

Referring to Fig. 4, the indenter can be prescribed with an indentation displacement $v$ or a force $F$ along the $y$ direction. In this study, the displacement-control method is used. The indentation displacement $v$ is prescribed on the indenter and then the force $F$ can be obtained. During
Table 1: Material constants

\begin{tabular}{|c|c|c|c|c|}
\hline \multicolumn{2}{|c|}{ Material } & $\begin{array}{l}\text { Young's } \\
\text { modulus } \\
E(\mathrm{GPa})\end{array}$ & $\begin{array}{l}\text { Poisson's } \\
\text { ratio } v\end{array}$ & $\begin{array}{l}\text { Yielding } \\
\text { strength } \\
S_{y}(\mathrm{MPa})\end{array}$ \\
\hline \multicolumn{2}{|c|}{$\begin{array}{l}\text { JIS SUS } 301 \mathrm{EH} \\
\text { stainless steel }\end{array}$} & 186 & 0.30 & 1250 \\
\hline \multicolumn{2}{|c|}{$\begin{array}{l}\text { Al-Mn } 3004 \\
\text { aluminum alloy }\end{array}$} & 68.82 & 0.34 & 257.77 \\
\hline \multirow{3}{*}{$\begin{array}{c}\text { 6061-T6 } \\
\text { aluminum alloy } \\
{[10-12]}\end{array}$} & $24^{\circ} \mathrm{C}$ & 68.5 & 0.33 & 276 \\
\hline & $260^{\circ} \mathrm{C}$ & 54 & 0.33 & 34 \\
\hline & $371^{\circ} \mathrm{C}$ & 40.3 & 0.33 & 12 \\
\hline
\end{tabular}

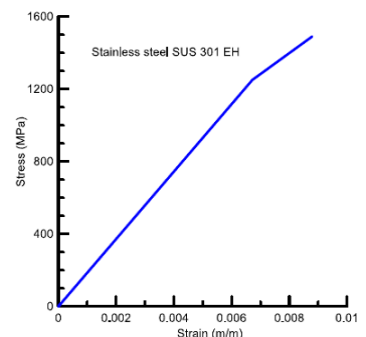

(a)

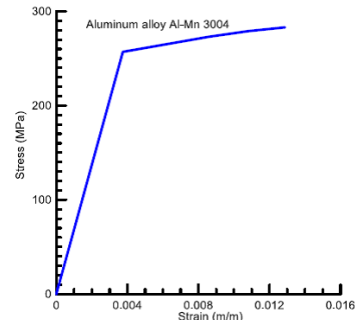

(b)

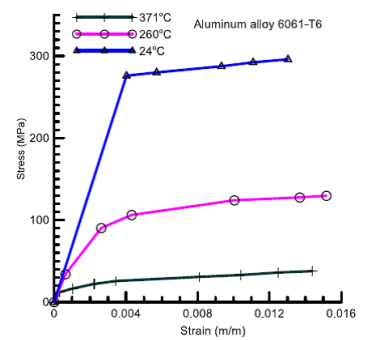

(c)

Figure 5: True stress-strain curves: (a) JIS SUS $301 \mathrm{EH}$ stainless steel; (b) Al-Mn 3004 aluminum alloy; (c) 6061-T6 aluminum alloy.

one loading cycle, the prescribed displacement is downward and upward. Five loading cycles of the indentation are used to simulate the practical operating motion of the button or switch.

The maximum displacement of the indentation is $v_{\text {max }}$. In this study, the maximum indentation $v_{\max }$ is larger than the arch height $H$.

\section{Methods of Analyses}

3.1 Finite Element Modeling In this paper, the analysis type of the snap-through deformation is quasi-static and non-linear. The large displacement, contact condition and elasto-plastic stress-strain relation are necessary to be considered. The finite element software ANSYS is adopted to solve the problem [13]. A typical finite element mesh is shown in Fig. 6. Due to relatively thin thickness of the arch, the SHELL93 elements (8-noded high-order shell element) are used for modeling the arch in the finite element simulation.

Due to the relative rigidity, the indenter is modeled as a rigid contact body. In ANSYS, contact conditions are given on the contact surfaces between the indenter and arch shell. TARGE170 and CONTA174 elements are used to simulate the contact surface and non-penetration condition. In the contact analysis, the shell thickness effect is considered in the numerical calculation. Also, the frictionless condition is 


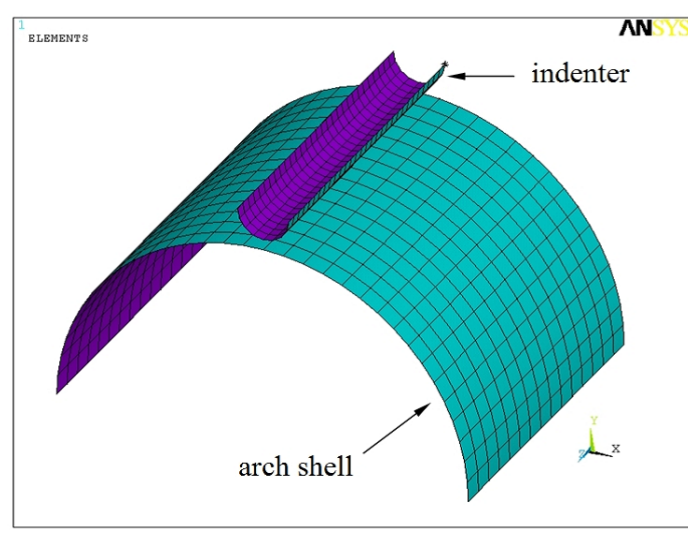

Figure 6: Finite element mesh

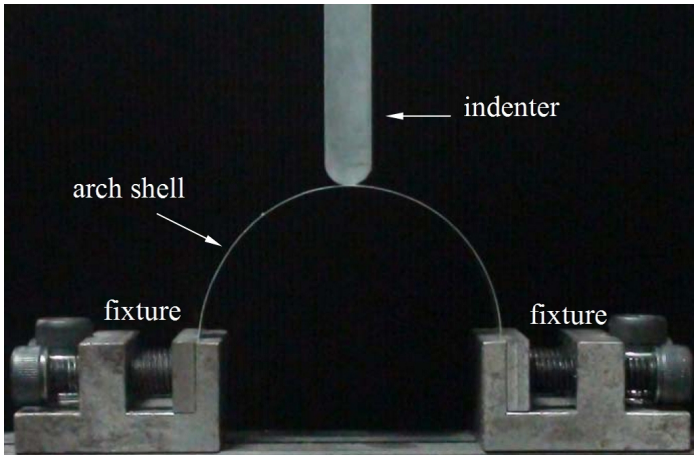

Figure 7: Sample and fixture in experiment

assumed on all contact surfaces.

In addition, the elasto-plastic analysis is considered because of the plastic deformation in the arch. The elastoplastic stress-strain curves (Fig.5) are inputted into ANSYS. The kinematic strain hardening rule with Bauschinger effect is considered for the cyclic loading conditions. The residual stresses made from the metal forming for the arch shape are neglected.

3.2 Experiments The experimental studies are established to ensure the accuracy of the finite element modeling. The MTS mechanical testing system (MTS Systems Co.) is adopted for the experiments. The sample and fixture are shown in Fig. 7. The indenter can move downward and upward to achieve the displacement-control motion for obtaining the snap-through deformation. Finally, experimental and finite element results will be compared for the modeling validation.

3.3 Design Parameters for Button and Switch The click ratio $R_{c}$ of the arch or dome is an important parameter for the button and switch design. Referring to Fig. 3(b), $R_{c}$ is defined as follows:

$$
R_{c}=\frac{F_{1}-F_{2}}{F_{1}} \times 100 \%
$$

where $F_{1}$ and $F_{2}$ denote respectively the force associated with $S_{1}$ and $S_{2}$ during the snap-through deformation. Larger $R_{c}$ value represents more obvious jump or click motion when people's finger presses on the button or switch.
However, the arch or dome may have large plastic deformation and bad performance with too large $R_{c}$. Referring to the past study [9], the click ratios are designed within the range $30 \%$ to $60 \%$ to obtain good click feeling and performance.

It is noted that the click ratio cannot be defined if $F_{1}$ is less than $F_{2}$. The situation, $F_{1}<F_{2}$, means that the snapthrough behavior is lost

During the snap-through deformation of the button or switch, $F_{1}$ is the maximum reaction force applied on the finger. If this force is too large, it will be hard for people to push the button or switch. On the contrary, the push feeling will be lost when the reaction force is too small. From the human factor engineering, the force $F_{1}=5 \mathrm{~N}$ is suggested for the light-force button design [14]. In ref.9, it is proposed that the range of $F_{1}$ should be designed from $1 \mathrm{~N}$ to $2.8 \mathrm{~N}$ for mobile communication products.

\section{Results and Discussions}

4.1 Validation of Finite Element Modeling Due to relatively thin thickness of the arch, the SHELL93 elements (8-noded high-order shell element) are used for modeling the arch in the finite element simulation. Due to the convenience for experimental investigations, the arch shell structure with large size is adopted. The arch dimensions are: $R=H=32.65 \mathrm{~mm}, W=15 \mathrm{~mm}, t=0.11 \mathrm{~mm}$, and $r=5 \mathrm{~mm}$. It is made of Al-Mn 3004 aluminum alloy. All experiments are done at room temperature.

During the experimental process, the indenter moves downward (forward) and upward (backward) in one loading cycle. Fig. 8 shows the force-displacement $(F-v)$ relations of the arch shell from experiments and finite element analyses. Because of the plastic strain in the arch, it makes the downward and upward paths different. In Fig. 8, when the indentation displacements are less than $0.041 \mathrm{~m}$, the finite element results agree well with experimental ones. Under the larger indentation, the large errors occur due to the complicated plastic phenomenon which the finite element analysis does not consider. As a result, Fig. 8 still supports the accuracy of the finite element modeling under allowable engineering simplifications.

Fig. 9 shows the historical deformations of the arch from experiments and finite element analyses. Similar deformed shapes are observed in these figures.

4.2 Effects of Working Temperature In this section, the arch shell structure with small size for the button or switch design is considered. The dimensions are: $R=2 \mathrm{~mm}$, $H=0.2 \mathrm{~mm}, W=3 \mathrm{~mm}, t=0.01 \mathrm{~mm}$, and $r=0.25 \mathrm{~mm}$. The 6061-T6 aluminum alloy is adopted as the arch material. Three temperature-dependent material properties at 24 ${ }^{\circ} \mathrm{C}, 260{ }^{\circ} \mathrm{C}$, and $371{ }^{\circ} \mathrm{C}$ in Fig. 5(c) are considered for discussing the temperature effects. The maximum indentation displacement $v_{\max }=0.28 \mathrm{~mm}$ is prescribed on the indenter. The indenter moves downward and upward for five loading cycles.

Fig. 10 shows the force-displacement relations of the arch shell at different temperatures. The figure's horizontal axis denotes the indentation displacement of the indenter. In Fig. 10(a), it shows that five loading cycles have the same 


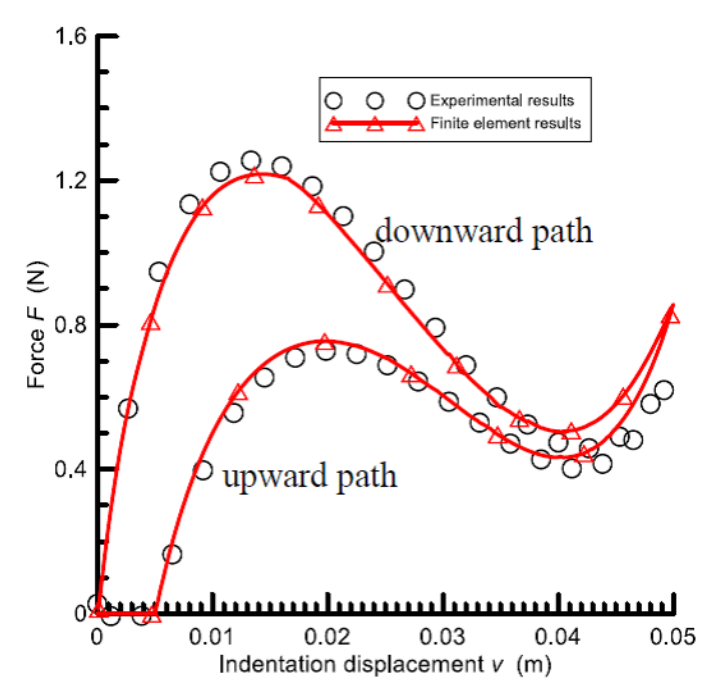

Figure 8: Force-displacement relations of arch shell from experiments and finite element analyses
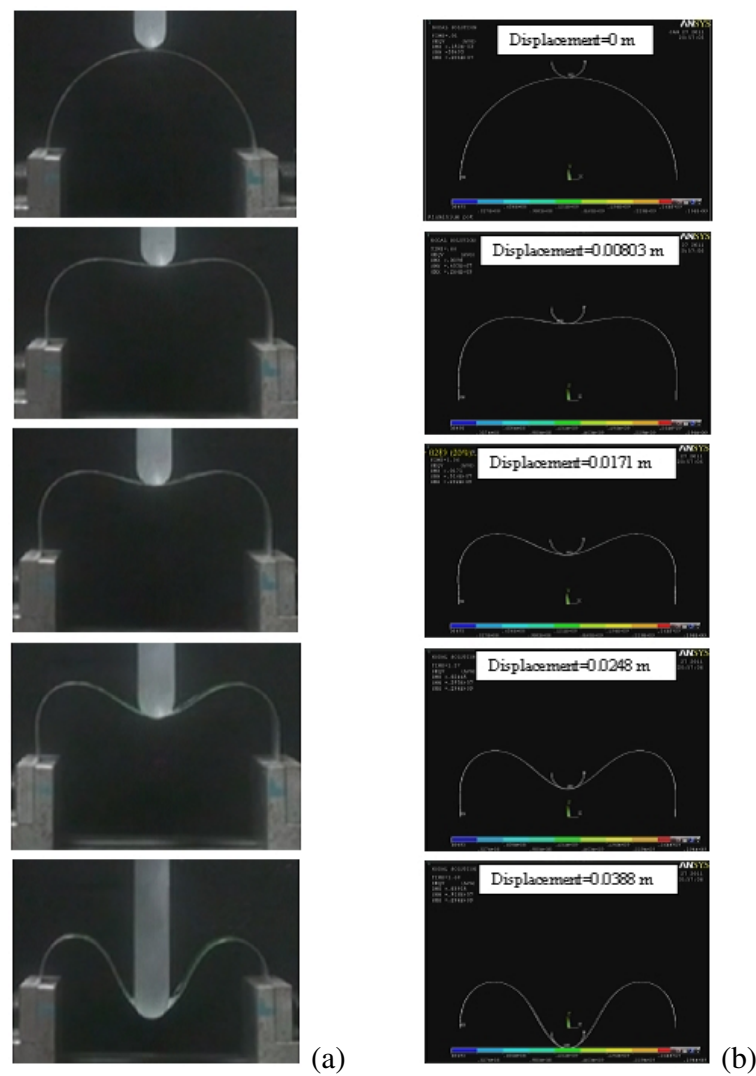

Figure 9: Snap-through results obtained from experiments (a) and ANSYS (b)

loading paths due to the pure elastic deformation at room temperature. Under higher working temperature $\left(260{ }^{\circ} \mathrm{C}\right)$ and plastic behaviors, Fig. 10(b) presents three different loading paths but the snap-through deformation still exists. In Fig. 10(c) the snap-through behavior is lost during the second to fifth loading cycles at $371{ }^{\circ} \mathrm{C}$. It represents that the arch cannot work at high temperature. The working temperature of the arch structure needs to be considered in the button and switch design.

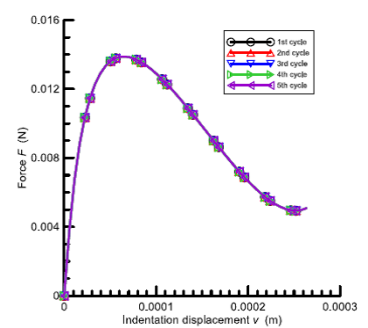

(a)

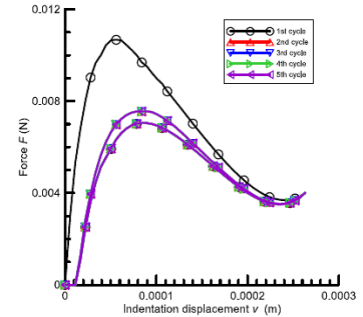

(b)

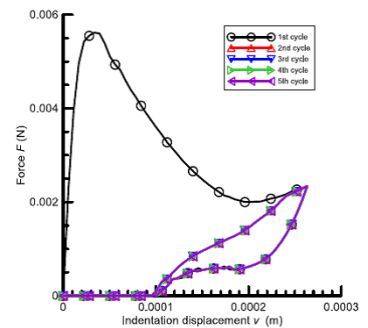

(c)

Figure 10: Force-displacement relation of arch shell at (a) $24{ }^{\circ} \mathrm{C}$; (b) $260{ }^{\circ} \mathrm{C}$; (c) $371{ }^{\circ} \mathrm{C}$.

4.3 Effects of Material Selection The arch shell structure with small size is also considered in this section. The dimensions are: $R=2 \mathrm{~mm}, H=0.2 \mathrm{~mm}, W=3 \mathrm{~mm}$, $t=0.05 \mathrm{~mm}$, and $r=0.25 \mathrm{~mm}$. The maximum indentation displacement is $v_{\max }=0.35 \mathrm{~mm}$. The indenter moves downward and upward for five loading cycles. All analyses are done at room temperature. Three material types, i.e. JIS SUS 301 EH stainless steel, Al-Mn 3004 aluminum alloy, and 6061-T6 aluminum alloy, are adopted for the arch.

Fig. 11 shows the force-displacement relations of the arch shell under different material types. In Fig. 11(a) and (b), the snap-through behavior is lost during the second to fifth loading cycles because of the large plastic strains. In Fig. 11(c), it keeps the snap-through behavior for all loading cycles. From above results, it is concluded that JIS SUS $301 \mathrm{EH}$ stainless steel is a good choice for the arch in the button and switch design. This stainless steel has high yield strength to reduce the plastic strain during the indentation loads. Aluminum alloys with lower yield strength are not suitable for the arch structure.

4.4 Cyclic Loading Fig. 11(c) presents the typical snap-through behavior of the arch shell. To observe clearly the results in Fig. 11(c), Fig. 12 depicts separately the behaviors of the first, second and third loading cycle. Due to the plastic strain in the arch, the downward and upward paths of the first loading cycle are different. Fortunately, after the first loading cycle, all remain loading paths almost follow the same curve due to the strain hardening. This behavior can keep the stable performance of the snap-through deformation of the arch. The JIS SUS $301 \mathrm{EH}$ stainless steel can provide the stable performance.

4.5 Geometrical Effects: $\boldsymbol{t}$ and $\boldsymbol{W}$ In this section, the effects of the geometrical parameters $t$ and $W$ on the click ratio $R_{c}$ and maximum force $F_{1}$ are discussed. The JIS SUS $301 \mathrm{EH}$ stainless steel are used as the arch material. The maximum indentation $v_{\max }=0.35 \mathrm{~mm}$ is prescribed on the 


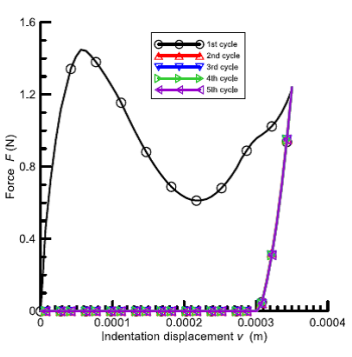

(a)

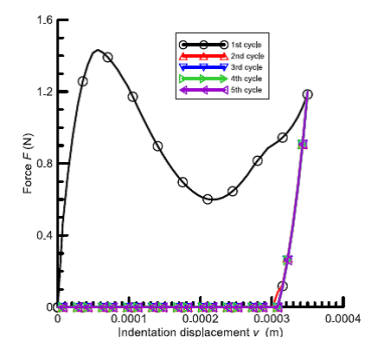

(b)

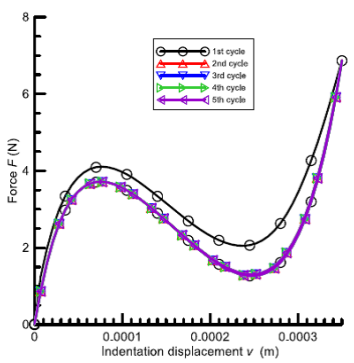

(c)

Figure 11: Force-displacement relation of arch shell made of (a) 6061-T6 aluminum alloy; (b) Al-Mn 3004 aluminum alloy; (c) JIS SUS 301 EH stainless steel.

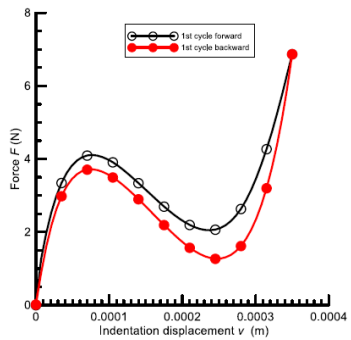

(a)

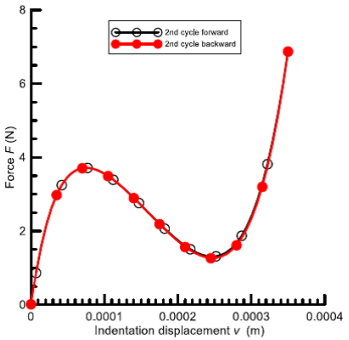

(b)

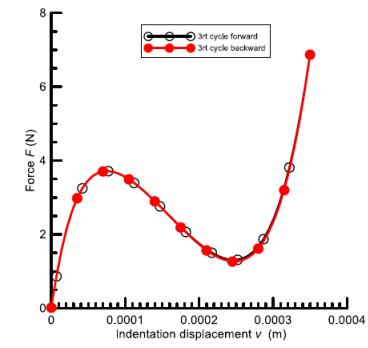

(c)

Figure 12: Results of Fig. 11(c). (a) first loading cycle; (b) second loading cycle; (c) third loading cycle.

indenter at room temperature. According to the conclusion in Section 4.4, only the results of the second loading cycle are discussed due to its stable performance.

First, the dimensions $R=2 \mathrm{~mm}, H=0.2 \mathrm{~mm}, W=3 \mathrm{~mm}$, and $r=0.25 \mathrm{~mm}$ are kept constant when the thickness $\mathrm{t}$ is a variable. Fig. 13 shows the second-cycle force- displacement relations of the arch shell with different thickness. All results keep the snap-through behaviors. In Fig. 14 and 15, it shows the arch thickness effects on the click ratio $R_{c}$ and maximum force $F_{1}$. The click ratio decreases when the arch thickness increases. In the range of $t<0.08 \mathrm{~mm}$, the force $F_{1}$ increases when the thickness increases. However, when $t>0.08 \mathrm{~mm}, F_{1}$ decreases due to the large plastic strain in

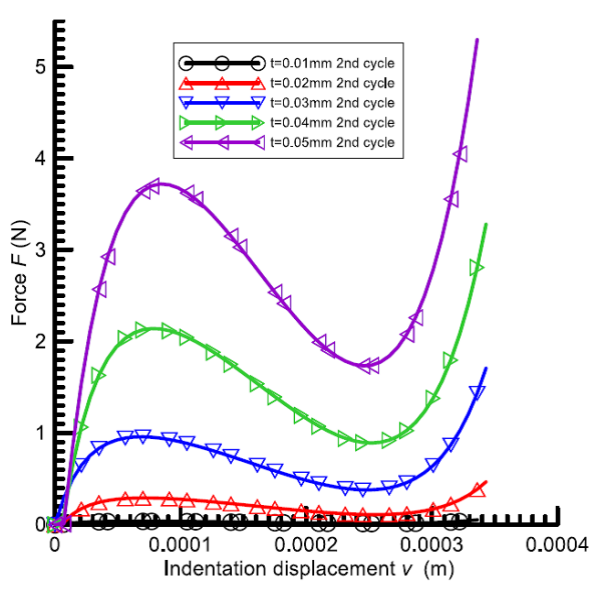

Figure 13: Force-displacement relations of arch shells with different thickness

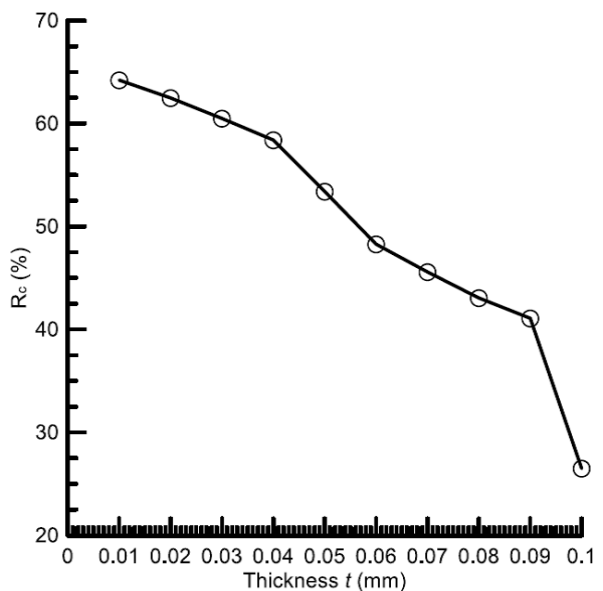

Figure 14: Variation of click ratio $R_{c}$ with different thickness

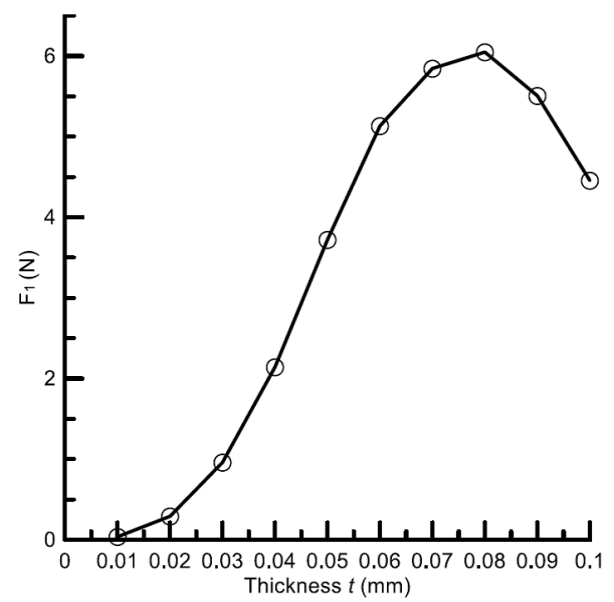

Figure 15: Variation of $F_{1}$ with different thickness

the arch.

When the width $W$ is considered as a variable, other dimensions $R=2 \mathrm{~mm}, H=0.2 \mathrm{~mm}, t=0.05 \mathrm{~mm}$, and $r=0.25 \mathrm{~mm}$ are kept constant. Fig. 16 shows the secondcycle force-displacement relations of the arch shell with different width. All curves have the same $S_{1}$ and $S_{2}$. Fig. 17 and 18 show the width effects. The click ratios almost keep 


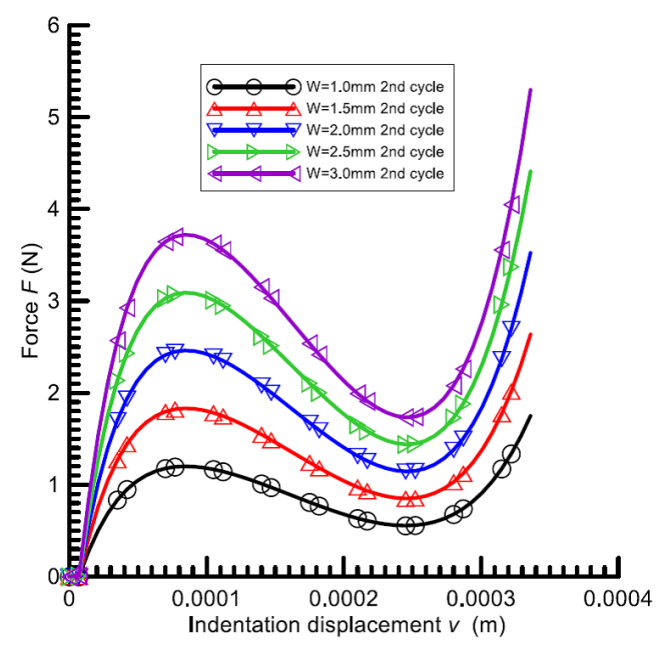

Figure 16: Force-displacement relations of arch shells with different width

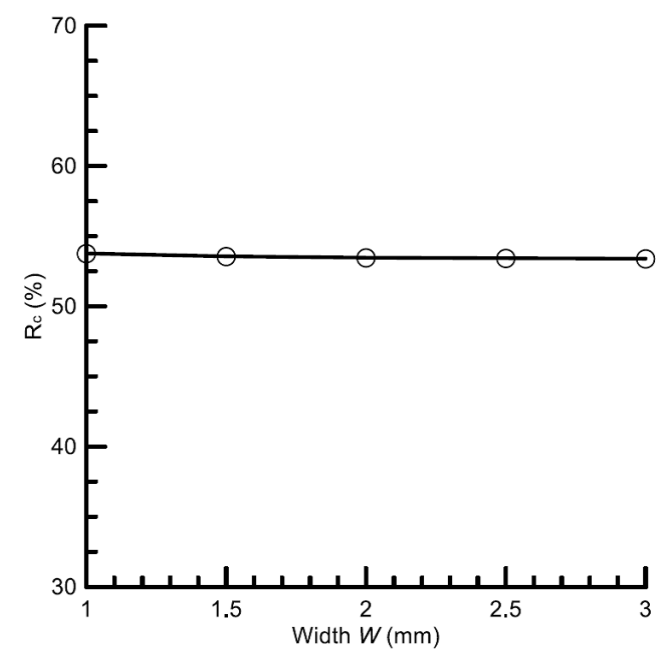

Figure 17: Variation of click ratio $R_{c}$ with different width

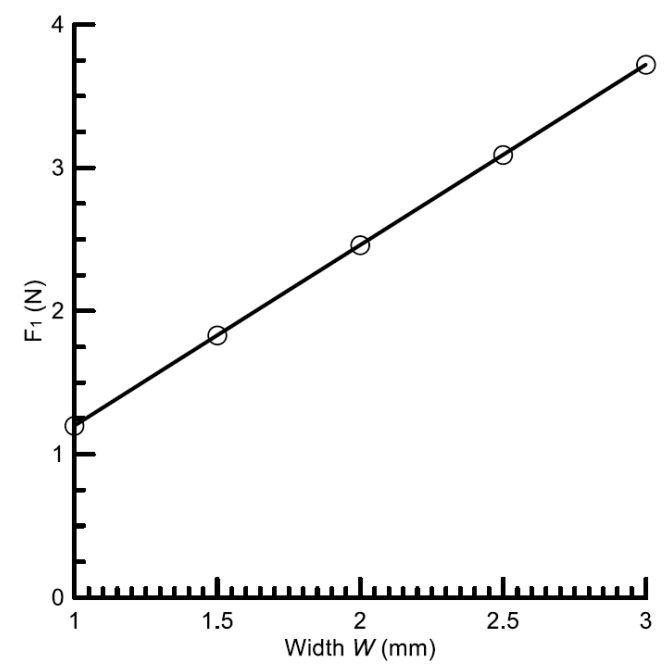

Figure 18: Variation of $F_{1}$ with different width

a constant value. The maximum force $F_{1}$ is propotional to the arch width.

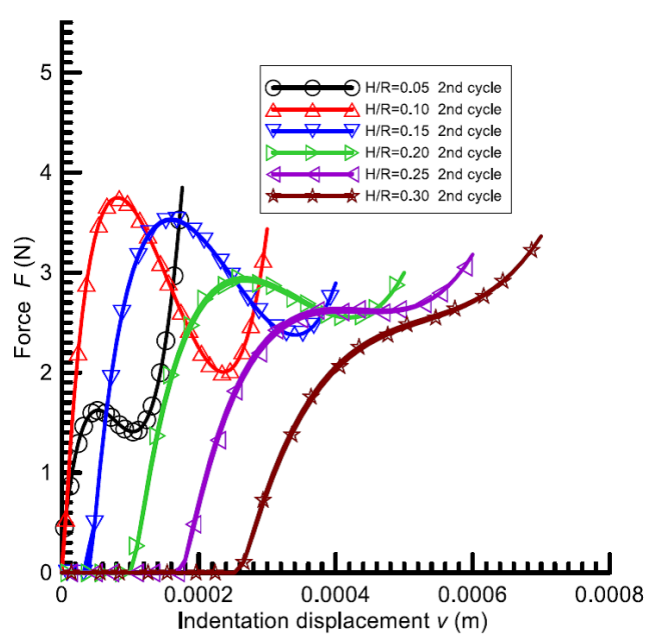

Figure 19: Force-displacement relations of arch shells with different $H / R$

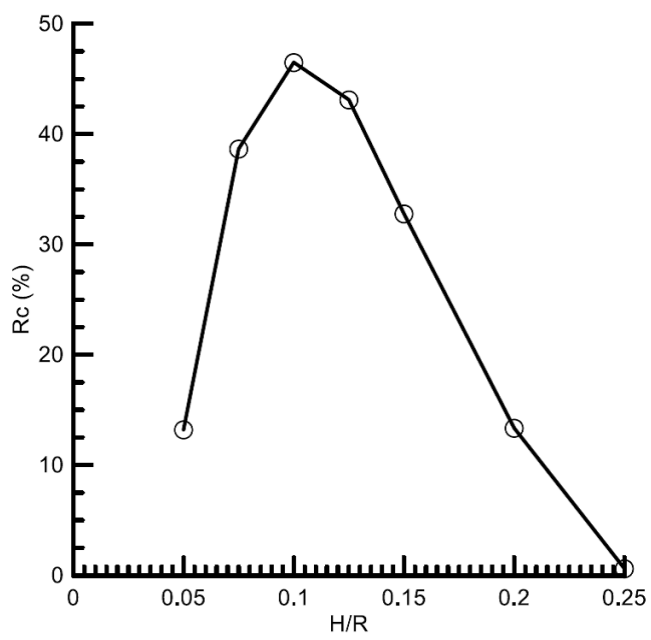

Figure 20: Variation of click ratio $R_{c}$ with different $H / R$

4.6 Geometrical Effects: $\boldsymbol{H} / \boldsymbol{R} \quad$ Following the study of Section 4.5, the effect of the height $H$ is discussed here. When $H$ is considered as a variable, other dimensions $R=$ $2 \mathrm{~mm}, W=3 \mathrm{~mm}, t=0.01 \mathrm{~mm}$, and $r=0.25 \mathrm{~mm}$ are kept constant. The maximum indentation is $v_{\max }=H+0.1 \mathrm{~mm}$ for each case.

Fig. 19 shows the second-cycle force-displacement relations of the arch shell with different $H / R$. In the case of $H / R=0.3$, the snap-through behavior is lost. In Fig. 20 and Fig. 21, it shows the effects of $H / R$ on the click ratio $R_{c}$ and maximum force $F_{1}$. When $H / R=0.1$, the maximum click ratio is obtained. However, the peak value of $F_{1}$ occurs when $H / R=0.15$.

4.7 Consideration of Eccentric Loading Referring to Fig. 22, the eccentric loading and position $e$ of the indenter are considered to observe the variations of $R_{c}$ and $F_{1}$. The geometry properties of the arch are $R=2 \mathrm{~mm}$, $H=0.2 \mathrm{~mm}, W=3 \mathrm{~mm}, t=0.05 \mathrm{~mm}$, and $r=0.25 \mathrm{~mm}$. The maximum indentation is $v_{\max }=0.35 \mathrm{~mm}$.

Fig. 23 shows the second-cycle force-displacement relations of the arch shell with different eccentric position $e$. 


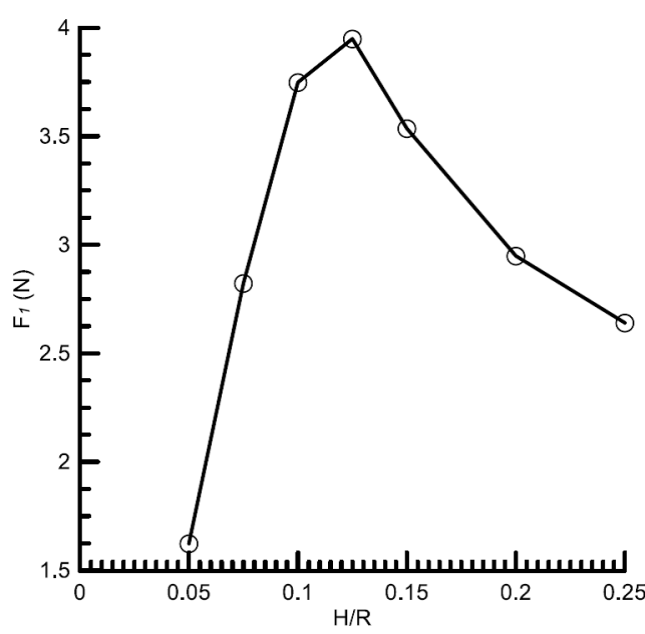

Figure 21: Variation of $F_{1}$ with different $H / R$

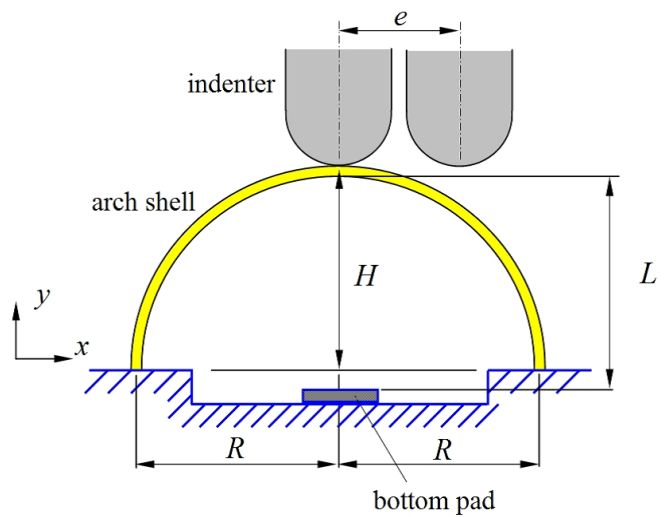

Figure 22: Considerations of eccentric loading and bottom pad

Due to different eccentric positions, the variations of $R_{c}$ and $F_{1}$ are shown in Fig. 24 and 25. When the indenter has eccentric position, the smaller $R_{c}$ and $F_{1}$ are obtained. In the case of $e / R=0.25$, the click ratio changes from $53 \%$ to $22 \%$. The snap-through behavior abates.

For the button or switch assembly, the allowable value of e is an important design issue. It depends on the product cost, human factors and many operating conditions. The maximum value of $e$ needs to obey the design criterion $R_{c}=$ $30 \% \sim 60 \%$.

4.8 Consideration of Bottom Pad In previous studies, only the single arch shell is analyzed. The arch shell is one of the key components of the button or switch as shown in Fig. 1. During the product design process, the assembly and interaction between the components need to be considered.

The bottom pad is another key component. As shown in Fig. 26, the bottom pad locates below the arch shell. Its function is to transfer the currents or signals when the arch shell touches the pad. In additions, the indentation from people's finger on the button or switch will be stopped by the bottom pad.

Referring to Fig. 22, the location of the bottom pad de-

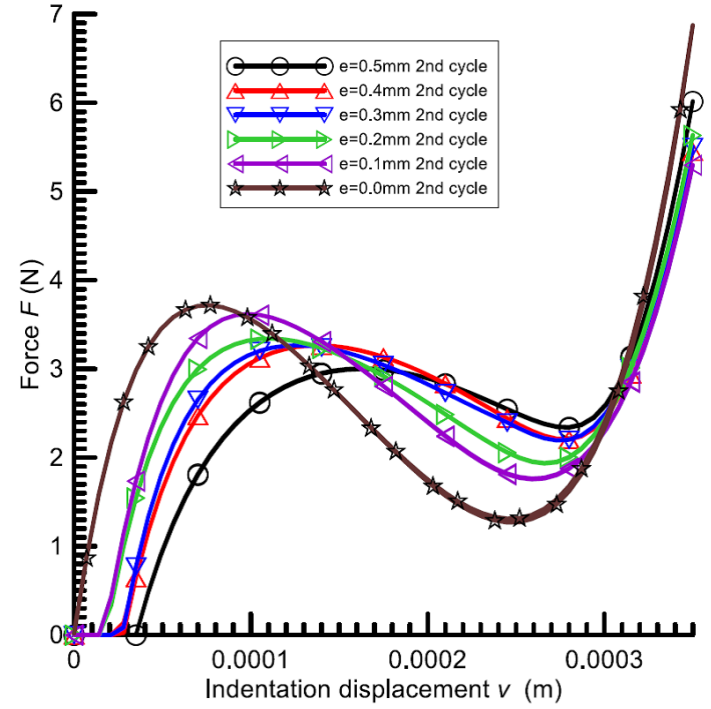

Figure 23: Force-displacement relations of arch shells with different eccentric position $e$

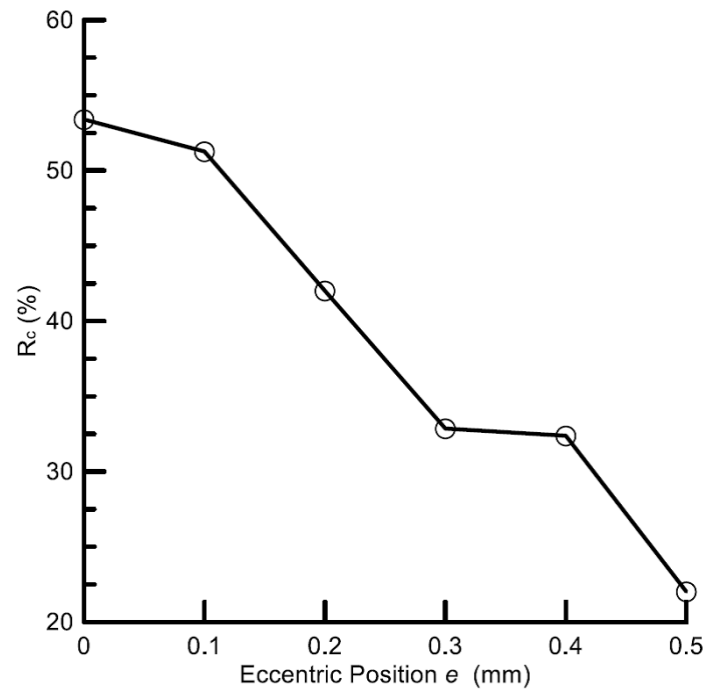

Figure 24: Variation of click ratio $R_{c}$ with different $e$

notes as $L$. Fig. 26 depicts the situations of $L=S_{2}, L>S_{2}$, and $L<S_{2}$. The condition $L=S_{2}$ is the optimal design for the button and switch due to the obvious and adaptive snap-through feeling. The cases of $L \gg S_{2}$ and $L \ll S_{2}$ are ill-conditions for the design. If $L \gg S_{2}$, the reaction force will increase rapidly before the arch touches the pad. So the button or switch will be hard to work. If $L \ll S_{2}$, the snap-through feeling will be weak or lost.

The allowable assembly tolerance of the dimension $L$ is an important design parameter. For example, the dimension and tolerance of $L$ can be defined as $L=S_{2} \pm \eta \Delta S$, where $\eta=0.2$ and $\Delta S=S_{2}-S_{1}$. However, if the value of $\eta$ or $\Delta S$ is smaller, the required precision and product cost tend to be higher.

\section{Conclusions}

According to the research results of this paper, the following design guidelines of the button or switch are provided for 


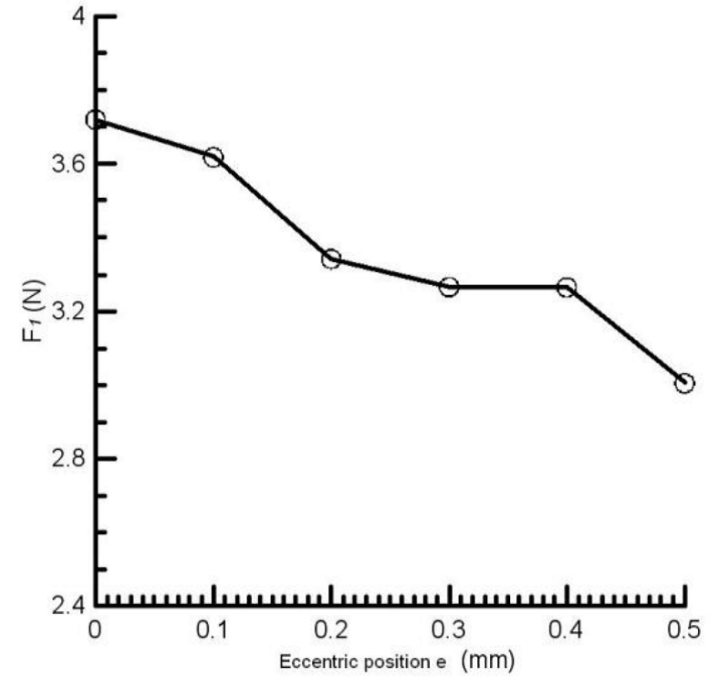

Figure 25: Variation of $F_{1}$ with different $e$

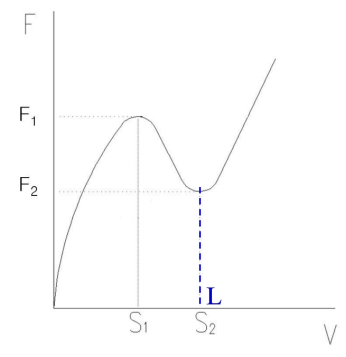

(a)

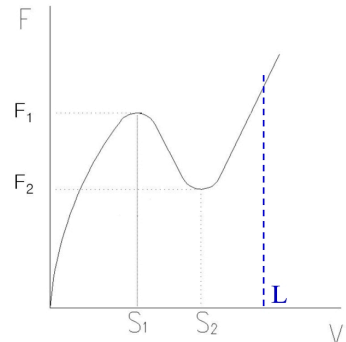

(b)

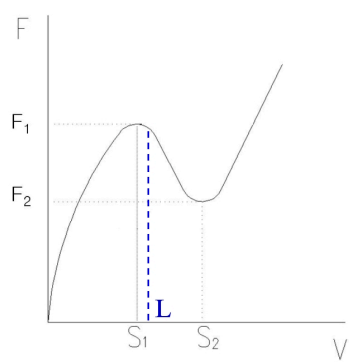

(c)

Figure 26: (a) $L=S_{2}$, (b) $L>S_{2}$, (c) $L<S_{2}$

product engineers:

(1) In the design process, the snap-through behavior of the single arch needs to be designed and confirmed first. Then the distance $L$ for the bottom pad should be designed as possible as $L=S_{2}$.

(2) The disappearance of the snap-through behavior needs to be avoided.

(3) The snap-through behavior of the arch is affected by many conditions such as working temperature, material type, geometry, and maximum indentation.

(4) When applying five loading cycles on the arch, it is concluded that the second cycle can be adopted as the structural performance. The different loading paths are due to the plastic strains.

(5) The arch cannot work at high temperature.
(6) The JIS SUS $301 \mathrm{EH}$ stainless steel is a good choice for the arch design. This stainless steel can provide the stable performance.

(7) When the indenter has the eccentric position, the snapthrough behavior abates.

(8) Referring to the past study [9], the click ratios are designed within the range $30 \%$ to $60 \%$ to obtain good click feeling and performance.

\section{References}

[1] D. O. Brush and B. O. Almroth, "Buckling of Bars, Plates, and Shells", McGraw-Hill, New York, 1975.

[2] G. Wempner and D. Talaslidis, "Mechanics of Solids and Shells: Theories and Approximations", CRC Press, New York, 2003.

[3] J. F. Mescall, "Large deflection of spherical shells under concentrated loads", ASME J. Appl. Mech., Vol.32, pp.936-938, 1965.

[4] J. V. Huddleston, "Finite deflections and snap-through of high circular arches", ASME J. Appl. Mech., Vol.35, pp.763769, 1968.

[5] K. J. Bathe and H. Ozdemir, "Elastic-plastic large deformation static and dynamic analysis", Comput. Struct., Vol.6, pp.81-92, 1976.

[6] R. D. Wood and O. C. Zienkiewicz, "Geometrically nonlinear finite element analysis of beams, frames, arches and axisymmetric shells", Comput. Struct., Vol.7, pp.725-735, 1977.

[7] I. Breslavsky, K. V. Avramov, Y. Mikhlin and R. Kochurov, "Nonlinear modes of snap-through motions of a shallow arch", J. Sound Vib., Vol.311, pp.297-313, 2008.

[8] K. Ninomiya, T. Yamaji, F. Sakiyama, M. Kaizu and T. Yokoyama, "Metal dome sheet for mobile phones", Fujikura Tech. Rev., Vol.99, pp.27-31, 2000. (in Japanese)

[9] T. Tomitsuka, S. Ajimura, T. Kawahira and Y. Noguchi, "Metal dome for a mobile communication terminal equipment", Fujikura Tech. Rev., Vol.104, pp.42-46, 2003. (in Japanese)

[10] K. G. Hoge, "Influence of strain rate on mechanical properties of 6061-T6 aluminum under uniaxial and biaxial states of stress”, Exp. Mech., Vol.6, pp.204. 1966.

[11] "MatWeb. Aluminum 6061-T6, MatWeb's Database of Material Properties", http://www . matweb.com/.

[12] S. F. Miller and A. J. Shih, "Thermo-mechanical finite element modeling of the friction drilling process", ASME J. Manuf. Sci. Eng., Vol.129, pp.531-538, 2007.

[13] “ANSYS Inc. ANSYS HTML Online Documentation”, SAS IP Inc., USA, 2005.

[14] R. H. Ma, "Human Factor Engineering", Peking University Press, Beijing, 2011. (in Chinese) 


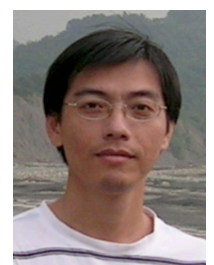

Thomas Jin-Chee Liu (Member) is an Associate Professor in Department of Mechanical Engineering, Ming Chi University of Technology. $\mathrm{He}$ received the $\mathrm{Ph} . \mathrm{D}$. degree in Mechanical Engineering from National Cheng Kung University in 2005 . His research interests are fracture mechanics, solid mechanics, finite element analyses, and computer-aided engineering (CAE). Professor Liu was a CAE engineer in ANSYS Department, Taiwan Auto-Design Company, during 1999 to 2001. He has many experiences in techniques of the finite element software ANSYS. Now, he dedicates himself to the engineering educations and industrial applications of ANSYS and CAE.

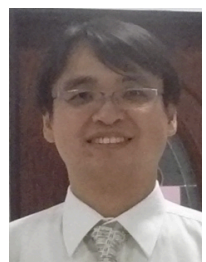

Nai-Pin Lin (Non-member) was a graduate student in Department of Mechanical Engineering, Ming Chi University of Technology. His research interests include the design and analysis of mechanical products. 